\title{
Construyendo capital social comunitario
}

\section{John Durston \\ Oficial de Asuntos Sociales División de Desarrollo Social, CEPAL}

Por capital social se entiende el conjunto de normas, instituciones y organizaciones que promueven la confianza y la cooperación entre las personas, en las comunidades y en la sociedad en su conjunto. En aquellas formulaciones del paradigma del capital social (y del neoinstitucionalismo económico en que éstas se basan en parte) que se concentran en sus manifestaciones colectivas, se plantea que las relaciones estables de confianza y cooperación pueden reducir los costos de transacción, producir bienes públicos y facilitar la constitución de actores sociales o incluso de sociedades civiles saludables. El capital social comunitario es una forma particular de capital social, que abarca el contenido informal de las instituciones que tienen como finalidad contribuir al bien común. Entre los propios autores fundacionales del paradigma del capital social hay dudas sobre la posibilidad práctica de construir este capital en grupos que carecen de él. Las comunidades campesinas de Chiquimula (Guatemala), atendidas por el proyecto antipobreza del Programa de Apoyo a los Pequeños Productores de Zacapa y Chiquimula (PROZACHI), mostraban una cultura relativamente individualista y de dependencia y dominación, pero que, paradójicamente, exhibía a la vez un amplio y dinámico repertorio de normas diversas, incluidas las que podrán servir de soporte simbólico a prácticas solidarias y recíprocas. Chiquimula parecía carecer de las instituciones del capital social. Pero al rescatar las prácticas institucionales del pasado y surgir nuevos contextos y oportunidades para desarrollar nuevas estrategias grupales, fue posible crear capital social en estas comunidades, con apoyo externo y capacitación, y convertir así a un sector excluido en un actor social del escenario microrregional. 


\section{I}

\section{El capital social}

\section{Una herramienta conceptual útil}

En círculos académicos y también en agencias de desarrollo se da actualmente un animado debate sobre la teoría del capital social. Este paradigma emergente pretende ser una suerte de teoría unificada que integra conceptos de diversos campos como los de la reciprocidad, las redes sociales, el desarrollo participativo y la gobernabilidad. Promete ser una valiosa herramienta para el análisis y la promoción del desarrollo de base campesino. El término capital social abarca las normas, instituciones y organizaciones que promueven la confianza y la cooperación entre las personas, en las comunidades y en la sociedad en su conjunto. En aquellas formulaciones de este concepto (y del neoinstitucionalismo económico que en parte las fundamenta) que se concentran en sus manifestaciones colectivas, se plantea que las relaciones estables de confianza y cooperación pueden reducir los costos de transacción (Coase, 1937), producir bienes públicos (North, 1990) y facilitar la constitución de actores sociales o incluso de sociedades civiles saludables (Putnam 1993a).

Este artículo examina una forma particular de capital social -el capital social comunitario-y el tema de su posible construcción, con el propósito de superar la pobreza y la exclusión política de comunidades rurales de América Latina.

En la definición seguida aquí, las normas culturales de confianza y las redes interpersonales de reciprocidad son "precursores" de aquellas instituciones, más complejas y orientadas por normas de bienestar común, que constituyen el capital social comunitario y que emergen de estos precursores a nivel de comunidad o de sistema social. Para algunos autores el capital social está constituido por todos los lazos interpersonales que puede activar un individuo, los que corresponden a lo que ya se conocía como redes egocentradas de reciprocidad difusa. Y, en el otro extremo, la definición de capital social comunitario (desde la perspectiva neoinstitucionalista) que se desprende de

El autor agradece los comentarios de Eugenio Lahera, Gonzalo Falabella, Samuel Morley, Maximiliano Cox, Roberto Guimarães, Orlando Peralta, Mario Chamalé, Alejandro Medina, Juan Sáez, Fernando Bazúa, Brent Metz, Fernando Rello, Margarita Flores, Iván Finot, Otto Fernández, Juan José Santibáñez, Rodrigo Contreras y Anthony Bebbington.
Putnam y de North — según la cual el capital social sería lo que produce cooperación y civismo, de modo que si hay civismo habrá capital social- ha sido correctamente calificada de tautológica o circular (Portes, 1998; Portes y Landholt, 1996).

Lo que aquí se plantea, en cambio, es i) que el capital social comunitario no es un recurso individual sino una forma de institucionalidad social (del conjunto, en este caso de la comunidad local); y ii) que los participantes del capital social comunitario (en forma explícita o implícita) plantean el bien común como objetivo, aunque éste puede no lograrse. Por otra parte, $y$ a diferencia de las instituciones formales de bien común (cooperativas, por ejemplo) que existen "en el papel", el capital social comunitario está constituido por normas, prácticas y relaciones interpersonales existentes y observables. Es la institucionalidad informal dentro y fuera de las organizaciones formales, a nivel de comunidad o sistema social más amplio, que determina cómo funcionan tales organizaciones en la práctica: lo que Firth (1963) llamó "organización social".

Aunque los miembros de la comunidad en que existe capital social comunitario comparten un discurso de cooperación para el bien común, queda por verse en la observación empírica si este fin se logra efectivamente. De hecho, pueden darse efectos contrarios al bien común, producto del capital social comunitario y de la reciprocidad interpersonal, como sucede en algunas comunidades étnicas o religiosas cuyas prácticas son excluyentes o que no respetan los derechos humanos fundamentales.

Finalmente, el concepto de reciprocidad es central al paradigma del capital social. El tratamiento antropológico del tema se ha construido sobre la base del clásico Essai sur le don de Marcel Mauss (publicado en $1950,{ }^{1}$ que tuvo un enorme impacto en la disciplina a partir de los años cincuenta. ${ }^{2}$ La importancia de la reciprocidad va más allá de su manifestación en las relaciones "diádicas" (Foster, 1961) entre dos personas; como principio regidor, se extiende a las re-

\footnotetext{
${ }^{1}$ En la bibliografía de este artículo se cita una versión inglesa de dicho ensayo (Mauss, 1990).

${ }^{2}$ Ni Putnam ni North hacen referencia a la obra de Mauss, que inspiró casi medio siglo de trabajo empiríco y teórico de antropólogos de varios países. Hasta ahora, este acervo conceptual de la antropología ha sido subaprovechado en el debate sobre el capital social.
} 
laciones institucionales formales e informales a nivel de la comunidad. En su ensayo, Mauss señala que en las sociedades premercantiles (y en menor grado en las nuestras, fuera del ámbito del mercado) operan sistemas de intercambio basados en obsequios (objetos, ayuda, favores) cuya compensación es obligatoria, pero no en forma inmediata ni siempre con equivalencia precisa, a diferencia de las transacciones mercantiles (Mauss, 1990). En un entorno socialmente delimitado (una sociedad tradicional o la mayoría de las comunidades campesinas actuales) y con relaciones de largo plazo establecidas a través de numerosas interacciones pasadas y con perspectiva de largo plazo, las relaciones tienden a darse en un mismo momento entre las mismas personas y familias en todos los ámbitos y en todas las instituciones de la vida humana - de carácter religioso, jurídico, político, familiar y económico-; en tal sentido son "fenómenos totales" (Mauss, 1990). Por este motivo la reciprocidad, que a primera vista podría parecer un fenómeno social menor entre muchos, es la base misma de las instituciones de capital social en contextos como el de la comunidad campesina.

\section{Dudas sobre la posibilidad de construir capi- tal social}

Curiosamente, existen dudas entre los propios autores fundacionales, como Robert Putnam, sobre la posibilidad práctica de construir capital social en grupos que carecen de él. Por ejemplo, Putnam (1993a) concluye que 'en la construcción de instituciones, el tiempo se mide en décadas', y que la creación de normas de cooperación y de participación cívica 'probablemente sea aún más lenta'.

Esta visión pesimista refleja la creencia en mecanismos de retroalimentación que reforzarían constantemente las normas y comportamientos existentes, llevando a todo sistema sociocultural a un equilibrio social positivo, de acumulación de capital social, o a uno negativo, el de una sociedad 'acívica'. Según Putnam, en el sur 'acívico' de Italia la sociedad llevaba siglos atrapada en una trayectoria negativa que se repetía, en que 'la desconfianza y la traición mutua, la dependencia vertical y la explotación...se han reforzado en círculos viciosos interminables...' (Putnam, 1993a).

\section{La construcción del capital social en el oriente de Guatemala}

\section{Las comunidades campesinas de Chiquimula: ¿Un panorama social institucionalmente va- cío?}

Las comunidades del oriente y del occidente de Guatemala suelen ser contrastadas en los mismos términos en que Putnam contrasta el sur y el norte de Italia. Se considera que las comunidades corporativas mayas del altiplano occidental tienden más a la toma colectiva de decisiones, mientras que las del oriente tienen una cultura individualista, con poca participación en organizaciones comunitarias.

En el decenio de 1990, el Programa de Apoyo a los Pequeños Productores de Zacapa y Chiquimula (PROZACHI) se aplicó durante siete años en ocho municipios del oriente ${ }^{3}$ con el fin de incrementar significa-

\footnotetext{
${ }^{3}$ Proyecto Ministerio de Agricultura y Ganadería/Fondo Internacional de Desarrollo Agrícola/Organización de Países Exportadores
}

tivamente los ingresos de los campesinos pobres de cerro y ladera en forma que fuese sustentable desde el punto de vista económico, ecológico e institucional (FIDA, 1998). Su estrategia de superación de la pobreza se centraba en facilitar el acceso de los campesinos al crédito bancario, pero también daba apoyo a través de su propio equipo de profesionales y técnicos (en asesoría y capacitación técnica agropecuaria, construcción de caminos, organización y gestión, conservación del medio ambiente, mejoramiento de la vivienda, participación de la mujer campesina en el desarrollo, comercialización, etc.).

de Petróleo/Programa Mundial de Alimentos/Países Bajos (Proyecto MAGA/FIDA/OPEP/PMA/Países Bajos). El área de acción del PROZACHI cubrió la mayor parte del Departamento de Chiquimula e incluyó zonas colindantes de dos municipios del Departamento de Zacapa. Como la gran mayoría de las aldeas atendidas estaban en Chiquimula, para simplificar nos referiremos a Chiquimula en este texto. 
Cuando comenzaron las actividades del PROZACHI, en 1991, el grupo al que estaban dirigidas -5000 familias campesinas que cultivaban principalmente maíz y frijol en unas 130 aldeas y villorrios de ladera- carecía en gran medida de organizaciones de base relevantes (FLACSO, 1993). Había algunos comités cívicos, pero eran principalmente pequeñas facciones o beneficiarios pasivos de organizaciones no gubernamentales caritativas. Hubo entonces reacciones de pesimismo y reticencia entre los funcionarios del PROZACHI ante la tarea de promover la participación de los beneficiarios en la toma de decisiones del Proyecto: se hallaban, en suma, ante un ejemplo más de las culturas acívicas descritas por Putnam.

\section{Reducción de escala y aumento de escala}

Sin embargo, se detectó luego que el patrón de asentamiento humano disperso en las aldeas de ladera del área de influencia del PROZACHI (véanse los mapas 1 y 2) correspondía a los llamados "grupos locales de ascendencia", es decir, pequeñas redes de parientes y vecinos que comparten una creencia en un ancestro común (Wolf, 1966). En cada aldea se repetían los mismos apellidos en una alta proporción de hogares, y algunos topónimos correspondían a los apellidos de las familias fundadoras (Durston, 1992). En estos grupos locales de ascendencia, que se encuentran en zonas montañosas de toda América Latina, los recién casa-

MAPA 1

Guatemala: Ubicación del área de influencia del PROZACH

E. PETDY

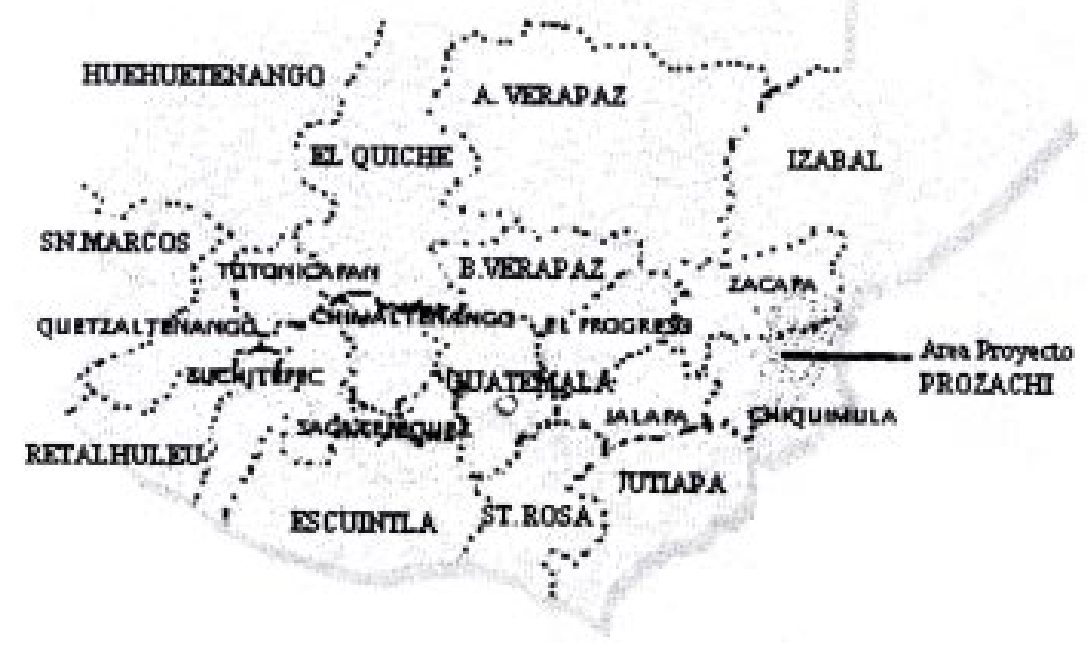

Fuente: FIDA (1998). 


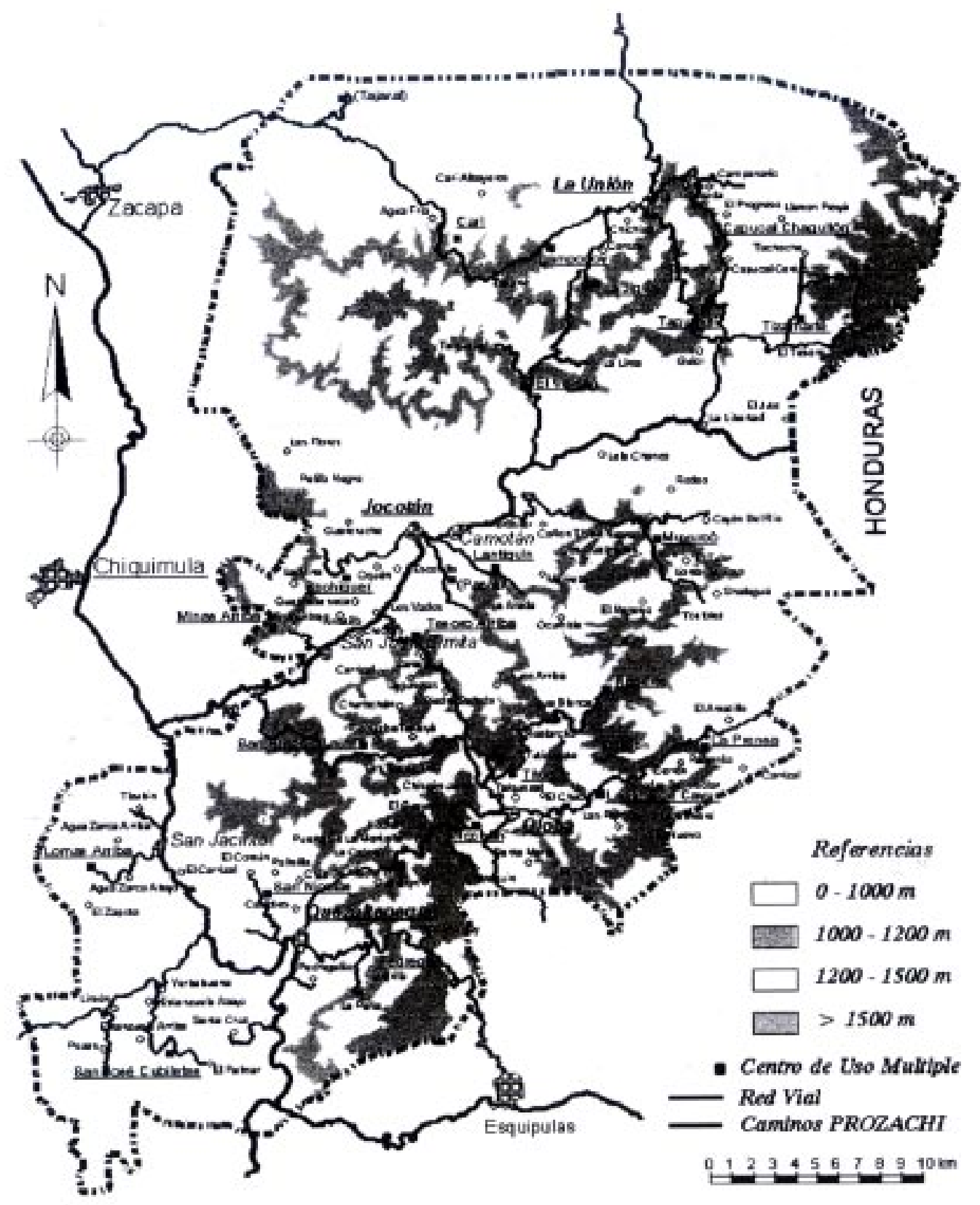

dos suelen residir cerca de los padres del marido y los lazos e interconexiones múltiples basados en el parentesco dan lugar a la cooperación y la confianza tanto horizontal como vertical.
El antropólogo guatemalteco Hugo Zelaya fue contratado para activar una "planificación participativa". Él diseñó un sistema de Grupos Núcleo (siete a 12 hogares unidos por vecindad cercana) que partici 
parían en la determinación de las necesidades y prioridades de quienes accederían a los servicios y beneficios del Programa (véase PROZACHI, 1995). Unos 40 promotores de desarrollo rural, que vivían inmersos en las aldeas de ladera, promovieron casa a casa los beneficios de la participación. En cada grupo se nombraron dos líderes para moderar sus reuniones y para servir de enlace con el PROZACHI. Se crearon más de 400 Grupos Núcleo, cuyas propuestas llegaron a modificar el plan operativo anual del Programa.

El período de mayor crecimiento de los Grupos Núcleo coincidió con un fuerte incremento en el número de hogares que recibieron crédito: de sólo 525 en 1992 pasaron a 3676 en 1994. Aunque fueron varios los factores que se combinaron para llevar a este gran cambio, los funcionarios del proyecto y los campesinos concuerdan en que la creación de tales Grupos Núcleo contribuyó fuertemente a ello.

Después de tres años de funcionamiento de los Grupos Núcleo, una asamblea de sus representantes propuso conformar una instancia de coordinación entre aldeas como una manera más eficiente de trabajar. Un estudio de asesoría diseñó un sistema de consejos comunitarios que abarcó a todos los comités y grupos organizados, partiendo del trabajo de base anterior pero sustituyéndolo en gran medida. Las iniciativas del personal del PROZACHI empezaron a ceder lugar a las propuestas espontáneas de los campesinos sobre apoyo a la organización y a sus acciones concretas.

El número de grupos con intereses más específicos, como los comités de agua potable o las microempresas asociativas, aumentó en 28\% entre 1991 y 1998 (cuadro 1). Se formaron más de cien consejos comunitarios y unos ocho comités de coordinación a nivel municipal. Lo que parece más importante es que $56 \%$ de estas organizaciones comunitarias fueron evaluadas como medianas o altamente autónomas en su gestión (cuadro 2). Y por último, en el primer semestre de 1998 se creó una asociación regional de representantes de estas organizaciones comunitarias rurales, que empezó a asumir un papel en el establecimiento de prioridades para el desarrollo rural en la región.

\section{Raíces del capital social en Chiquimula}

Varios aspectos del proceso de formación de capital social en Chiquimula son factores que ayudan a explicar en retrospectiva por qué fue posible construir dicho capital en esta región acívica en mucho menos de las décadas que plantea Putnam. El primero de estos factores fue la presencia de los grupos locales de as-
CUADRO 1

Chiquimula y Zacapa (Guatemala): Crecimiento de la organización campesina en cinco niveles territoriales, 1991-1998

\begin{tabular}{lrr}
\hline Nivel territorial & 1991 & 1998 \\
\hline Grupos locales de ascendencia (aldea) & - & 440 \\
Grupos de interés específico & 380 & 487 \\
Nivel comunitario (interaldeas) & - & 129 \\
Nivel municipal & - & 8 \\
Nivel regional & - & 1 \\
\hline
\end{tabular}

Fuente: Programa de Apoyo a los Pequeños Productores de Zacapa y Chiquimula (PROZACHI).

CUADRO 2

Chiquimula y Zacapa (Guatemala):

Consolidación organizacional en las comunidades participantes, 1998

\begin{tabular}{lcccc}
\hline Microrregión & $\begin{array}{c}\mathrm{N}^{\circ} \text { de } \\
\text { aldeas }\end{array}$ & \multicolumn{3}{c}{$\begin{array}{c}\text { Nivel de autonomía } \\
\left(\mathrm{N}^{\circ} \text { de aldeas }\right)\end{array}$} \\
\cline { 3 - 5 } & & Incipiente & Intermedio & Consolidado \\
\hline Jocotán & 49 & 14 & 17 & 18 \\
Olopa & 35 & 18 & 13 & 4 \\
La Unión & 19 & 11 & 3 & 5 \\
Quezaltepeque & 26 & 14 & 12 & - \\
Total & 129 & 57 & 45 & 27 \\
Porcentaje & $100 \%$ & $44 \%$ & $35 \%$ & $21 \%$ \\
\hline
\end{tabular}

Fuente: Programa de Apoyo a los Pequeños Productores de Zacapa y Chiquimula (PROZACHI).

cendencia, repositorios de reciprocidad y precursores de los Grupos Núcleo.

Un segundo factor fue la identidad compartida. Usualmente el campesinado del oriente de Guatemala es considerado "ladino" (no indígena), pero hace apenas una generación en gran parte de las comunidades rurales predominaban las instituciones sociales de la cultura maya Ch'ortí, cuyo idioma se halla aún hoy en varias aldeas. En el censo de 1994, más de 70000 residentes del Departamento de Chiquimula se autoidentificaron como indígenas. La conciencia de estas raíces y el fortalecimiento del idioma y la cultura Ch'ortí fueron promovidos por el movimiento maya nacional desde mediados de los años noventa (Metz, 1998). También son elementos de identidad el ser todos "campesinos", ser de la misma zona y pertenecer a la misma comunidad. Las identidades de los campesinos de ladera en Chiquimula son entonces híbridas y variables, pero todas se definen en oposición a los centros urbanos dominantes, lo que las transforma en una fuerza 
de cohesión y confianza entre los miembros de las diferentes comunidades rurales.

El tercer factor fue la memoria histórica. En los años sesenta, la Misión Belga de la Iglesia Católica creó varias cooperativas agrícolas y comités de promoción de infraestructura social en las mismas aldeas que fueron visitadas por el PROZACHI tres décadas más tarde. Tales organizaciones, reprimidas hacia finales de los años sesenta, fueron recordadas por los campesinos al discutirse las ventajas y peligros de participar en las nuevas organizaciones que promovía el PROZACHI.

El cuarto factor fue justamente la reducción de la represión. En los años noventa el Ejército comenzó a retirarse gradualmente de la participación directa en la toma de decisiones políticas a nivel nacional, proceso que culminó con la firma de los Acuerdos de Paz a finales de 1996. En las aldeas de Chiquimula, los comisionados militares y las patrullas de autodefensa civil dejaron de existir, y se cerró la base militar regional, con lo cual la situación estructural se volvió mucho más propicia para las organizaciones campesinas.

El quinto factor fue el inicio del empoderamiento de las mujeres campesinas. La inscripción por primera vez en el Registro Civil de cientos de mujeres con el apoyo del PROZACHI, la formación de grupos productivos de mujeres que recibieron crédito y asesoría (Lundius, 1998), y su incorporación a las discusiones comunitarias, liberaron y capacitaron recursos humanos antes excluidos. Estos cambios fortalecieron el proceso de autodiagnóstico y la democratización del liderazgo, elementos esenciales del capital social.

El sexto factor fue la interacción de los campesinos con los promotores de desarrollo rural, que vivían inmersos en las aldeas y cuya presencia en el entorno social local y regional, según se sabía, iba a durar varios años. Los promotores participaban inevitablemente en los "sistemas totales de prestaciones" y de relaciones recíprocas de las cuales nos habla Mauss. Se generaron así relaciones estables, fortalecidas por la expectativa de interacciones futuras y por los lazos afectivos que surgieron de la historia de prácticas de ayuda mutua y la devolución de estos favores en otros momentos (véase Evans, 1996). Por un lado, la demostración de compromiso personal del promotor con las personas de la comunidad estimuló la participación de los campesinos en las actividades del PROZACHI, que se vio prestigiado. Por otro, las ayudas diversas prestadas por los promotores fortalecieron las relaciones de reciprocidad y solidaridad entre los mismos vecinos del lugar.

Los seis factores señalados contribuyeron a la creación de capital social, pero la materialización de su potencial se debió a las iniciativas del PROZACHI y, a partir de marzo de 1997, del Fondo de Inversión Social (FIS). ${ }^{4}$ En primer lugar, se diseñaron programas de capacitación, con el propósito de crear capital social mediante el fortalecimiento de destrezas sociales, de diagnóstico, de comunicación y de planificación. Ya en 1995, y a solicitud de los campesinos, se realizaron más de 400 eventos de capacitación organizacional. Para llevarlos a cabo hubo que adaptar los métodos y materiales existentes a las condiciones locales, diseñar nuevas técnicas y publicar una serie de panfletos para debatirlos en grupo.

En segundo lugar, el PROZACHI y el FIS dieron a los campesinos oportunidades de hacer uso de estas nuevas destrezas y asociaciones de capital social para obtener beneficios materiales inmediatos del Programa y del Fondo. Y en tercer lugar, tanto el PROZACHI como el FIS protegieron a las embrionarias instituciones campesinas de capital social comunitario mientras aún predominaba el clientelismo autoritario en la región, e intervinieron cuando ellas se vieron amenazadas por actores sociales hostiles.

\section{III}

\section{Lecciones sobre la construcción}

\section{de capital social}

La lectura hecha aquí de la experiencia de Chiquimula sugiere que es preciso efectuar algunas modificaciones en el paradigma del capital social, en lo que se refiere a los obstáculos para su construcción. Estas modificaciones teóricas, a su vez, tendrían repercusiones en las políticas.
En primer lugar, la confianza y la reciprocidad que se extienden más allá del hogar nuclear, y que se

\footnotetext{
${ }^{4}$ El FIS provee gratuitamente de infraestructura social física (principalmente caminos, escuelas y centros de salud) a comunidades rurales organizadas.
} 
encuentran en los grupos locales de ascendencia, se asocian con los lazos de parentesco cercano y con largos años de interacción con vecinos, y por ende es probable que existan en todas las sociedades campesinas (véase Wilson, 1997).

En segundo lugar, y en consonancia con la teoría de los juegos más moderna, la repetición frecuente de ejercicios de confianza y cooperación entre los campesinos creó una disposición cada vez mayor — al principio lenta e insegura, después acelerada - a cooperar recíprocamente en la vida comunitaria (Axelrod, 1997). La confianza se construye sobre el pasado, no sobre el futuro: sobre la experiencia de cumplimiento anterior que prueba la confiabilidad de las personas, no sobre acuerdos y contratos de promesas para el futuro. En situaciones de conflicto pasado que habían minado la confianza (como en Chiquimula), estos ejercicios de cooperación crearon una historia reciente de confiabilidad como base para la colaboración futura.

En tercer lugar, la reciprocidad vertical resultó ser una parte necesaria de la construcción del capital social, tanto dentro de la comunidad como fuera de ella. Para casi todos los teóricos del capital social, las relaciones de reciprocidad vertical son lo contrario del capital social, porque unen a personas de poderes desiguales y son, por ende, asimétricas. Sin embargo, la distinción entre la reciprocidad vertical y la horizontal no es tan nítida en el mundo real.

\section{Bases del capital social en la reciprocidad ver- tical campesina}

En las comunidades campesinas de Chiquimula, algunos jefes de hogar, especialmente los de mayor edad, lideran grupos - o "cuasi grupos" (Mayer, 1966) menos definidos- de numerosos hogares de los parientes y vecinos que les rodean, que les sirven para acumular tanto bienestar material como prestigio. De esta manera, por un lado la reciprocidad vertical y el faccionalismo son intrínsecos a las redes interpersonales de la comunidad campesina; pero por otro, el liderazgo basado en esta reciprocidad vertical puede ser la base de la cooperación y la ampliación de la organización más allá de la aldea local. Estos líderes de los cuasi grupos son los empresarios del capital social, y gestionan los recursos humanos de sus parientes y vecinos, ante los cuales tienen obligaciones y deben rendir cuentas.

En Chiquimula, las destrezas sociales y prácticas de cooperación que se desarrollaron en los Grupos Núcleo fueron transferidas por los líderes al nivel re- gional, donde estos representantes negociaban con sus pares de otras organizaciones. Por ende, las técnicas para crear cooperación también ayudaron a aumentar la escala de la organización campesina. Estos nuevos líderes, formalizados en los Grupos Núcleo, ${ }^{5}$ y los coordinadores regionales que fueron elegidos entre ellos, también crearon una densa red de comunicaciones dentro de un sistema social disperso en el cual la represión había aumentado el aislamiento.

\section{Clientelismo y reciprocidad vertical para el capital social}

El clientelismo vertical que ligaba las aldeas de ladera a la sociedad mayor no desapareció cuando se retiró la presencia militar directa. Continuó operando en forma autoritaria, tanto a través del caciquismo en la política partidaria como de las relaciones económicas de dependencia con terratenientes e intermediarios en los centros urbanos. Incluso las reformas para la descentralización administrativa de la toma de decisiones oficiales y la gestión de nuevos recursos fiscales, a pesar de su importancia potencial como complemento del capital social local, sirvieron para fortalecer a los caciques locales, que tenían acceso privilegiado a esos recursos y espacios (véase Galeano y Yore, 1994). En suma, la presencia continuada del clientelismo autoritario en la zona hizo necesaria alguna instancia de apoyo externo al incipiente capital social comunitario.

Sin embargo, este tipo de apoyo externo es también una forma de clientelismo. $\mathrm{Al}$ respecto, es pertinente la distinción que hace Jonathan Fox entre el clientelismo autoritario y el semiclientelismo (Fox, 1996). A diferencia de lo que sucede con el clientelismo autoritario, los actores predominantes en relaciones semiclientelistas rechazan el uso de la fuerza, y promueven sus intereses a través de la provisión de servicios a sus clientelas o ganan su apoyo político en una causa compartida y negociada.

El PROZACHI y el FIS se acercan a la definición que hace Fox de las agencias externas semiclientelísticas. Sus funcionarios se identificaban con los beneficiarios y proveyeron relaciones más democráticas de reciprocidad vertical, que facilitaron el acceso de los campesinos a recursos públicos en expansión y a aliados reformistas en el nivel central (véase Tendler, 1997). Ambas instituciones contribuyeron al proceso de democratización local y microrregional y su actuación fue clave en la creación de las condiciones necesarias para el surgimiento del capital social comunitario campesino. Actuaron al mismo tiempo para potenciar la trans- 
formación de la reciprocidad y la identidad locales en instituciones de capital social campesino, y para aprovechar los cambios en el contexto nacional, al establecer un paraguas protector de este capital social embrionario.

Aunque parte de su labor fue la constitución de una institucionalidad formal para la participación, mucho más importante fue su impacto en la institucionalidad informal (véase el gráfico 1), la cual, como señala Putnam (1993a), penetra las organizaciones formales y suele volcar su funcionamiento real en contra del desarrollo democrático. La introducción del semiclientelismo en un contexto de nuevas oportunidades debilitó el clientelismo autoritario. El capital social comunitario surgió de la sinergia entre este semiclientelismo y los precursores de reciprocidad en los grupos locales de ascendencia campesinos; en su momento también contribuyó a debilitar el clientelismo autoritario en la zona, con el surgimiento de un actor social campesino a nivel regional y la resultante democratización de las relaciones en la región.

\section{Repertorios culturales y normas alternativas}

En términos más generales, la experiencia de Chiquimula sugiere algunas revisiones a la visión de determinismo cultural y de equilibrios sociales negativos que forman parte del marco teórico del capital social postulado por Putnam y otros. Para Putnam, las normas culturales de desconfianza y de dependencia son tradiciones rígidas que se resisten al cambio estructural de las instituciones formales. Pero los campesinos en Chiquimula mostraron tener un repertorio cultural muy amplio, con normas alternativas que incluían no sólo la desconfianza y la dependencia, sino también normas de autonomía y de responsabilidad de sus líderes hacia sus parentelas y sus comunidades.

Tanto North como Putnam reconocen la existencia de mecanismos de retroalimentación entre los subsistemas social y cultural, pero la argumentación de ambos con respecto al capital social es fundamentalmente determinista, puesto que atribuye casi todas las conductas a factores culturales. A partir de un estudio sobre dos casos realizado en Italia, Putnam llega a una conclusión universal, según la cual existe un "doble equilibrio social": el equilibrio de las sociedades con una gran dotación de capital social y el equilibrio de las que se caracterizan por la desconfianza, la traición

\footnotetext{
${ }^{5}$ Cerca de 800 en el área de influencia del PROZACHI.
}

y el autoritarismo (Putnam, 1993a, p. 177). En esencia, este modelo, derivado implícitamente de la teoría del equilibrio económico, postula que la dependencia de la trayectoria anterior supone un fortalecimiento constante de estos dos conjuntos de normas y prácticas contrapuestas, cuya dirección quedó determinada en el pasado (Putnam, 1993a, p. 179).

Sin embargo, las culturas, lejos de ser conjuntos coherentes e inmutables de reglas y creencias, cambian constantemente e incluyen una enorme gama o repertorio (Swidler 1986) de "sentencias" alternativas en desuso y de fragmentos de "sentencias" que son reelaborados y recombinados diariamente por personas y grupos debido a la necesidad de adaptarse a los cambios en el entorno que enfrentan constantemente las culturas. Estas opciones normativas, que se mantenían sumergidas durante la época de clientelismo autoritario represivo, reemergieron cuando cambió el clima sociopolítico. Cuando algunos líderes continuaban exhibiendo comportamientos de pasividad y subyugación inculcados en la trayectoria anterior, y no tomaban iniciativas independientes o seguían obteniendo beneficios personales de su papel de nexo con el mundo exterior, la comunidad (especialmente los jóvenes) les recordaba estos otros principios tradicionales, haciendo cambiar el comportamiento de los líderes o, en algunos casos, cambiando a los líderes mismos. La presencia de estos repertorios culturales optativos también explica por qué algunos cambios en la estructura social (en este caso, la desarticulación del sistema de los comisionados militares y la emergencia de elites nacionales reformistas) pudieron conducir a cambios rápidos en las normas relativas a la cooperación y el capital social.

\section{Coevolución de estrategias}

El segundo aspecto débil del argumento de Putnam en contra de la posibilidad de construcción rápida del capital social es la idea de que los sistemas sociales "acívicos" tienden siempre hacia un equilibrio negativo con un alto grado de desconfianza y egoísmo. Sin embargo, el sistema sociopolítico regional de Chiquimula dejó rápidamente de ser puramente autoritario y empezó a transformarse en semiclientelista, en lo que la teoría de la complejidad llama una fase de transición en un sistema basado en agentes (Cowan y otros, 1994). En esta visión, los sistemas sociales nunca tienden naturalmente al equilibrio, sino que las estrategias de múltiples actores sociales coevolucionan constan- 
temente, a veces con lentitud, a veces con rapidez, y las relaciones e instituciones sociales emergen de esta coevolución (Arrow, 1994).

La fase de transición sistémica en Chiquimula significó el fin de un período de cambio lento, es decir, del período largo de clientelismo autoritario y represivo. Las condiciones nuevas desataron cambios muy rápidos en las estrategias y relaciones de los actores antiguos y nuevos, y terminaron con la dependencia de la trayectoria anterior y aceleraron la consolidación del capital social campesino y de su presencia como actor social regional (gráfico 1).

La coevolución acelerada de las estrategias de los actores sociales empezó en los primeros meses de 1997, cuando el PROZACHI y el FIS estimularon la formación de comités para la coordinación de las organizaciones comunitarias rurales en los escenarios municipales. Los alcaldes autoritarios y sus partidos cooptaron estos comités mediante la participación de funcionarios locales y nacionales en las mesas directivas. Los campesinos reaccionaron en algunos municipios, proponiendo que los funcionarios se limitaran a funciones de asesoría. Los alcaldes pararon esta estrategia, quejándose al gobernador departamental. Los campesinos boicotearon entonces las reuniones de sus propios comités de coordinación municipal. Los funcionarios regionales del FIS reaccionaron con una propuesta al gobierno nacional de aceptar el planteamiento de los campesinos. Con esta legitimación oficial, los campesinos formaron nuevos comités municipales en los que los funcionarios públicos sólo tuvieron el papel de asesores. Las estrategias de los alcaldes divergieron: algunos siguieron resistiendo la dilución de su control local, mientras que otros se aliaron con estos nuevos actores

GRAFICO 1

Chiquimula (Guatemala): Cambios en la institucionalidad informal en proyectos con participación campesina

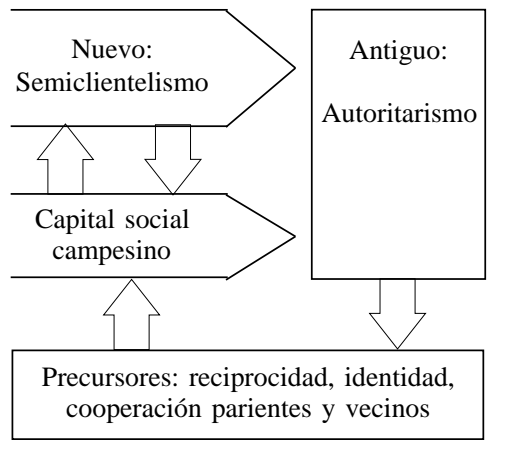

Nivel territorial

Nacional

Regional

Comunitario

Grupo local de ascendencia sociales, proveyendo espacio y transporte para la realización de sus reuniones de coordinación. Y el FIS comenzó a canalizar su apoyo financiero y técnico hacia la construcción de infraestructura social a través de estos comités más autónomos y de los consejos comunitarios.

El concepto de equilibrio de los sistemas económicos y sociales ha sido cuestionado por las versiones más recientes de la teoría de los sistemas adaptativos y complejos basados en agentes, aplicable a una amplia gama de áreas, desde los ecosistemas a los mercados bursátiles. Esta línea teórica de reciente desarrollo plantea dos cuestionamientos al concepto de equilibrio dual de Putnam y North, provenientes de la teoría de la complejidad. En primer lugar, como afirma Durlauf (1997), la dependencia de la trayectoria anterior sólo se mantiene hasta que el sistema reciba un nuevo impacto. En un comienzo, éste puede ser limitado, pero si modifica la estructura de oportunidades de distintos actores, los cambios que resulten de la conducta de éstos pueden terminar borrando las antiguas trayectorias y creando otras nuevas. En segundo término, Arrow (1994) afirma que la teoría de la complejidad ha demostrado que las instituciones económicas y sociales no son un producto de la planificación ni de la tendencia al equilibrio, sino que derivan de la evolución simultánea de las estrategias de numerosos agentes que interactúan en términos de colaboración y de competencia. Por lo tanto, un sistema puede mantenerse estable por un tiempo, hasta que una masa crítica de agentes perciba un cambio, opte por nuevas estrategias y descubra cómo aplicarlas para que se adecuen a las de los demás. Este cambio de estrategias puede dar origen a una etapa de transición gradual dentro del sistema, en la que un cambio institucional muy rápido abre nuevos caminos. Esto es contrario a lo que ocurre en el caso de los cambios lentos, unidireccionales y reforzadores que se dan mientras subsiste la dependencia de una determinada trayectoria.

En Chiquimula, el desarrollo del capital social respondió a la vez a mensajes culturales y cambios estructurales. Por una parte, la campaña de los funcionarios del PROZACHI en favor de la colaboración evocaba antiguos pero conocidos principios de buena vecindad y los imperativos de una difusa reciprocidad, mientras que los llamados a la paz y la democracia planteaban ideas nuevas que entraron en conflicto con las relaciones establecidas de las estructuras de clientelismo autoritario. Como resultado, los dirigentes comenzaron a tomar iniciativas en lugar de esperar que les dieran órdenes, y los más jóvenes empezaron a 
rechazar a los intermediarios locales autoritarios y corruptos, recordándoles y recordando a la comunidad la antigua norma según la cual debían ante todo ser leales a los suyos.

Cualquier cambio en el equilibrio de poder entre las elites políticas nacionales puede abrir posibilidades de poner fin a la dependencia de la trayectoria anterior en estructuras clientelistas y autoritarias. Esto significa que el surgimiento de nuevas formas de semiclientelismo no obedece exclusivamente a la acción de reformadores progresistas, ya que incluso los relativamente conservadores pueden tener motivos para aliarse con grupos locales de base. Unos y otros contribuyeron a la rápida transición que se produjo en Chiquimula a mediados de los años noventa.

La transición de un sistema autoritario a un sistema semiclientelista en el área consistió en la aceleración de las reacciones y la adaptación de las estrategias de los actores sociales, después de una etapa inicial de cambio lento, y dio origen a nuevas normas, conductas y relaciones que hicieron más rápida la consolidación del capital social campesino y, fundamentalmente, crearon un nuevo contexto institucional.

Este proceso de fortalecimiento del capital social campesino fue una cadena de acción y reacción de al menos tres de los principales actores sociales: las elites urbanas provinciales, los organismos externos de lucha contra la pobreza y las comunidades de las zonas montañosas. La historia de la construcción del capital social campesino en Chiquimula también es la historia de la creación de un nuevo actor social y de la transición desde las normas, conductas y relaciones típicas del clientelismo autoritario regional al semiclientelismo.

Tal cambio sólo pudo darse gracias a que las comunidades de las zonas montañosas ya habían desarrollado (o reconstruido) su capital social rudimentario al comienzo de este proceso, por lo que podían intervenir y adaptarse como actores sociales, reaccionando a las estrategias tanto de sus adversarios como de sus aliados. Sin ser el entorno ideal para el capital social campesino, el semiclientelismo toleró su existencia y permitió su creciente fortalecimiento y acumulación.

\section{Etapas en la evolución de las estrategias so- ciales}

La evolución simultánea de las estrategias de los actores sociales en Chiquimula, en los siete años considerados, puede dividirse en cuatro etapas.

\section{a) Cambio lento y clientelismo autoritario (1991-} 1993)

En esta primera etapa, los partidos políticos clientelistas y las elites económicas locales dominan a la población en virtud de sistemas clientelistas autoritarios y con apoyo del ejército; los organismos de lucha contra la pobreza se limitan a la prestación tecnocrática de servicios a beneficiarios pasivos en los pueblos, en el marco de una relativa estabilidad del sistema microrregional.

\section{b) Transición incipiente (1993-1996)}

Esta etapa se inicia con la decisión del PROZACHI de adoptar una nueva estrategia, que fomenta el desarrollo de las organizaciones campesinas embrionarias en torno a grupos pequeños dedicados a la producción y la comercialización, e invita a la población a participar en la planificación de proyectos por intermedio de los Grupos Núcleo, dentro del ámbito protegido de las actividades de un proyecto y ofreciendo beneficios materiales a corto plazo.

Los partidos políticos clientelistas expresan la alarma que esto les provoca a través de los caciques políticos locales, pero mientras parte del personal de los proyectos va siendo sustituido, el PROZACHI puede seguir ejecutando sus nuevas actividades gracias a alianzas con los grupos nacionales reformistas. Los campesinos de las zonas montañosas comienzan poco a poco a colaborar entre ellos y a cultivar una alianza con el PROZACHI que, a su vez, y en respuesta a solicitudes de estos campesinos intensifica su labor de capacitación organizacional.

c) Evolución simultánea y acelerada de las estrategias de los actores (1997)

A comienzos de 1997, el PROZACHI y el FIS fomentan la creación de consejos rurales, con representación de varios pueblos, y la de comités municipales coordinadores de dichos consejos.

En febrero y marzo de 1997, el FIs ofrece capacitación y da apoyo a las organizaciones campesinas en la presentación de propuestas de proyectos para el financiamiento de obras de infraestructura social y productiva.

Entre abril y junio de 1997, las organizaciones rurales se reúnen con el fin de organizar comités municipales coordinadores. Los partidos políticos de orientación clientelista logran dominar la mayoría de los comités, mediante la participación de funcionarios de los gobiernos locales y del gobierno nacional en sus 
directorios. Los habitantes de la zona proponen, entonces, que la participación de los funcionarios se limite a la de prestar asesoría. Los partidos políticos protestan ante el gobernador regional (departamental) por intermedio de los alcaldes, arguyendo que eso sería ilegal. Los habitantes de la zona responden con un boicot de las reuniones de los comités municipales. Ante esto, los funcionarios locales del FIs proponen al gobierno nacional que se acepte la propuesta de la población del lugar. El fIS organiza un seminario regional, destinado a explicar las ventajas de esta alternativa en el marco histórico posterior a la firma del acuerdo de paz, en el que participan funcionarios de la gobernación y las municipalidades.

\section{d) Surgimiento del semiclientelismo (1997-1998)}

A mediados de 1997, los consejos rurales crean nuevos comités municipales coordinadores, lo que relega a los funcionarios públicos a una función de asesoría. Los alcaldes adoptan diferentes estrategias; mientras algunos se oponen terminantemente a la innovación, otros se alían con los nuevos actores sociales, a los que ofrecen instalaciones y transporte para celebrar reuniones. El FIS aporta financiamiento directo a estos consejos autónomos.

A fines de 1997 y comienzos de 1998, un partido político pide apoyo a la organización campesina en la campaña electoral para el cargo de alcalde. La organización se niega a dárselo, por no haber participado en el proceso de selección del candidato.

A mediados de 1998, ocho comités municipales coordinadores se unen para crear una organización

\section{IV}

\section{Conclusiones}

\section{1. ¿Es posible crear capital social?}

¿Demuestra lo ocurrido con el PROZACHI y el FIS que es posible desarrollar capital social en situaciones en las que predominan normas y prácticas "acívicas"? La respuesta a esta pregunta depende en parte de si los logros descritos anteriormente constituyen o no capital social según la estricta definición presentada al comienzo de este artículo, es decir, si se trata o no de instituciones basadas en la confianza y la cooperación, que representan bienes públicos económicos o que contribuyen al bien público cívico. En el caso de Chiquimula, regional. El PROZACHI subcontrata a la organización campesina para que mantenga caminos y preste otros servicios. Las organizaciones campesinas locales dan muestras de más iniciativa: concretamente, presentan propuestas de proyectos de infraestructura y participan en los programas de administración conjunta de escuelas. Un dirigente campesino es elegido miembro de un consejo municipal. La organización campesina microrregional pide prestada al PROZACHI su maquinaria pesada para mantención de caminos. El PROZACHI da inicio a una nueva etapa (PROZACHI 2), en la que organizaciones campesinas locales, municipales y regionales participan en un proceso de administración conjunta destinado a dar sustentabilidad institucional a las organizaciones y empresas creadas en el período 19911998.

Por lo tanto, la acelerada transformación de las estrategias de los actores en la etapa de transición y la modificación sistémica que ésta produjo son algunas de las posibles causas de la relativa rapidez con que se desarrolló el capital social en Chiquimula. Otra fue la existencia de metodologías de desarrollo de capital social comunitario, que permitieron alcanzar los objetivos propuestos intencionalmente. A su vez, esto permitió al personal del PROZACHI y el FIS dar formación a los actores sociales neófitos de las zonas montañosas, a tiempo para que pudieran aprovechar las oportunidades y desafíos que se dieron a mediados de los años noventa en Chiquimula; esta metodología estándar dio resultados más rápidos que los cambios espontáneos o la confianza en los efectos secundarios de otros tipos de medidas públicas (Putnam, 1993b).

aunque el tema del beneficio económico merecería un estudio más a fondo, ${ }^{6}$ la respuesta es positiva (recuadro 1).

\footnotetext{
${ }^{6}$ Sin embargo, los datos preliminares indican que en la mayoría de las familias campesinas mejoró tanto la disponibilidad de insumos como el acceso a los mercados y la productividad, En el marco del PROZACHI se crearon alrededor de 200 nuevas microempresas asociativas, supuestamente con economías basadas en la transacción. Por último, se redujeron las imperfecciones de los mercados para las ventas al por mayor de los pequeños cafetaleros y para los jornaleros rurales.
} 
Recuadro 1

HIPÓTESIS SOBRE LA CONSTRUCCIÓN DE CAPITAL SOCIAL

- En todos los grupos locales pequeños, en todas partes, hay normas y prácticas de reciprocidad. La cooperación y la rendición de cuentas de quienes desempeñan funciones directivas forman parte de la mayoría de las culturas, como consecuencia de una selección a varios niveles; la iteración de prácticas adecuadas suele traducirse en cooperación.

- Las culturas presentan repertorios cambiantes con contenidos contradictorios. El cambio sistémico puede provenir de la cultura o de la estructura social. La eliminación o reducción de la represión posibilita el resurgimiento del capital social, ya que los sistemas complejos no tienden al equilibrio, sino que cambian constantemente a través de una "coevolución" de las estrategias de diversos actores.

- Las modificaciones de las elites nacionales ofrecen posibilidades de surgimiento de capital social local. Las alianzas con sectores reformistas del gobierno abren posibilidades de desarrollo de capital social.

- La confianza, la cooperación, la identidad compartida y la reciprocidad creadas en la comunidad pueden reproducirse entre los dirigentes, a fin de "trasladar" el capital social de pequeñas comunidades al plano microrregional.

- Actualmente existen metodologías y técnicas de desarrollo de capital social que permiten crearlo a voluntad, en lugar de esperar a que surja como un subproducto de otras actividades o como un fenómeno espontáneo.

En primer lugar, el desarrollo intencional de capital social campesino se tradujo en el logro (relativo) de un objetivo limitado: la adquisión de poder por los campesinos de las zonas montañosas, como parte del intento por mitigar la pobreza en forma sostenida. En segundo lugar, esta adquisición de poder condujo al surgimiento de un nuevo actor social microrregional, con la incorporación a las actividades cívicas de un sector social hasta entonces excluido de la adopción de decisiones públicas, lo que por sí solo constituye un refuerzo de la democracia local y regional en Guatemala. En tercer lugar, la consolidación de las organizaciones campesinas territoriales se tradujo en una rápida transición de una estructura represiva y autoritaria a un sistema semiclientelista en estado de flujo, lo que representa un avance hacia el establecimiento de una sólida sociedad civil microrregional y abre la posibilidad de nuevos avances en la misma dirección.

El principal propósito de este estudio ha sido mostrar, en un caso concreto, por cuáles razones y en qué grado no es válido el principio teórico de que el desarrollo de capital social a partir de cero siempre es un proceso lento y una tarea prácticamente imposible. El análisis de este caso también apunta a la necesidad de reexaminar la teoría del capital social y ofrece algunas conclusiones sobre políticas y medidas concretas encaminadas a dar poder a los actores comunitarios rurales. Las prácticas sugeridas para fomentar el capital social comunitario se resumen en el recuadro $2 .^{7}$

\section{Reflexiones finales}

A fin de cuentas, el estereotipo de la cultura campesina de Chiquimula tiene algo de cierto. Es, efectivamente, una cultura relativamente individualista y de dependencia y dominación, pero al mismo tiempo, paradójicamente, también es una cultura con un amplio y dinámico repertorio de normas diversas, incluidas las que pueden servir de soporte simbólico a prácticas solidarias y recíprocas. Chiquimula parecía carecer de las instituciones del capital social, pero solamente mientras no se rescataban las prácticas institucionales del pasado y surgían contextos y oportunidades propicios para desarrollar nuevas estrategias grupales.

La dependencia de la trayectoria cultural anterior resultó ser un obstáculo menor para la construcción de capital social campesino que el obstáculo estructural constituido por el clientelismo autoritario, pues cedió rápidamente al cambio desatado en la estructura política por la presencia de nuevos actores sociales en Chiquimula y por los acuerdos de paz.

\footnotetext{
7 Varias de las sugerencias presentadas en el recuadro 2 fueron incorporadas en el diseño del "PROZACHI 2", un nuevo proyecto (19982002) para consolidar y asegurar la sustentabilidad institucional de la autogestión campesina en la zona, que cuenta con el apoyo del Gobierno de los Países Bajos.
} 
Recuadro 2

MEDidAS PARA DESARROLlAR CAPITAL SOCIAL COMUNITARIO RURAL

- Realizar una búsqueda de normas y prácticas sobre confianza, reciprocidad y cooperación en grupos locales de ascendencia en culturas campesinas aparentemente dominadas por el individualismo y el "familismo".

- Analizar y aprovechar condiciones favorables para el resurgimiento del capital social, creadas por el debilitamiento del clientelismo autoritario.

- Realizar una "excavación arqueológica" del capital social, a fin de identificar episodios anteriores de desarrollo que puedan haber sido reprimidos o desalentados, pero que se han conservado en la tradición oral colectiva.

- Iniciar un proceso de desarrollo de aptitudes sociales en grupos de ascendencia integrados por un máximo de 10 a 15 hogares unidos por relaciones de parentesco, residencia y reciprocidad. Asegurar que la mayoría de estos grupos, no sólo las facciones dominantes, esté representada en ejercicios de desarrollo de capital social en los que participe toda la comunidad.

- Ofrecer reiteradas oportunidades de creación de lazos de familiaridad y cooperación a nivel comunitario.

- "Proteger" a las asociaciones campesinas incipientes del clientelismo autoritario regional, tanto político como económico. Perfeccionar en esta etapa protegida las aptitudes sociales de los líderes; procesar los conflictos que surgen del faccionalismo en las organizaciones.

- Estar pendiente de las perturbaciones que puedan sufrir los sistemas de clientelismo autoritario, que debilitan la dependencia de la trayectoria negativa y ofrecen posibilidades de resurgimiento del capital social campesino.

- Desarrollar una rápida capacidad de respuesta en los proyectos y programas, para contrarrestar las acciones de los actores clientelistas en procesos de transición. Fomentar el desarrollo de la capacidad de negociación estratégica de los dirigentes campesinos.

- Otorgar prioridad al fomento del sentido de misión entre los funcionarios de un proyecto, orientado al desarrollo de capital social autónomo.

- Fomentar la reflexión sobre las redes interpersonales existentes entre el gobierno y la sociedad civil. Facilitar el acceso de las comunidades marginadas a redes que ofrecen la información y los servicios a los que tienen acceso los estratos más integrados.

- Tomar medidas para asegurar que el capital social cívico de las comunidades pobres ofrezca beneficios materiales a corto plazo y, a la vez, contribuya a la habilitación en el terreno político.

La ausencia aparente de capital social en las aldeas de ladera escondía precursores importantes de cooperación, que fueron aprovechados mediante la reducción inicial de las actividades del PROZACHI a nivel de los grupos locales de ascendencia y su posterior ampliación a los niveles comunitario, municipal y microrregional. Una "arqueología del capital social" detectó la memoria histórica de los éxitos de una generación anterior.

Los emergentes actores sociales campesinos, apoyados por aliados institucionales externos, aprovecharon las oportunidades creadas por los cambios en las elites nacionales, participaron en una rápida coevolución de las estrategias de diversos actores sociales microrregionales y ayudaron a echar las bases de una nueva estructura microrregional semiclientelista más propicia al desarrollo de una sociedad civil democrática y participativa.

La aplicación de los métodos existentes de capacitación en gestión organizacional ${ }^{8}$ y el papel de colchón que desempeñaron los proyectos de desarrollo hicieron posible la construcción deliberada del capital social, en contraste con el postulado de Putnam de que éste es siempre el resultado indirecto de acciones públicas destinadas a otros fines. La combinación de factores señalada permitió construir capital social comunitario campesino en Chiquimula. Lleve o no en el

\footnotetext{
${ }^{8}$ Sobre metodologías de capacitación en gestión organizacional, véase: Banco Mundial (1997), Cruz (1996), IAF (1995), RIMISP (1996 y 1998), Rivera (1996), Toledo (1994) y Torres (1998).
} 
futuro ese capital social comunitario a conseguir los beneficios que se esperan de él (economías de transacción, bienes públicos y constitución de una sociedad civil fuerte), lo que está claro es que sí fue posible crearlo en unos pocos años.

El análisis realizado aquí sugiere que, entre los seis factores identificados como las bases de la construcción de capital social en Chiquimula, tres fueron claves: la existencia de formas de reciprocidad en la cultura campesina; el surgimiento de una "ventana de oportunidad" de cambios favorables a la constitución de un actor social campesino, y la internalización de capacidades de autogestión comunitaria.

Todo parece indicar que no existen comunidades rurales intrínsecamente "acívicas" que carezcan del potencial de construcción de capital social, aunque este potencial esté sumergido en la memoria histórica y en partes del repertorio cultural actualmente en desuso. Lo que debe añadirse, sin embargo, es que las formas particulares de reciprocidad en una comunidad dada pueden diferir de aquellas que se manifestaron en Chiquimula, basadas en el parentesco en grupos locales de ascendencia relativamente estables. Pero en esos casos también otras manifestaciones de reciprocidad, asocia- das a formas propias de vecindad, pueden ser convertidas en ladrillos culturales y sociales para construir las instituciones del capital social comunitario (recuadro 2).

Por otra parte, aunque los cambios en el contexto político en Chiquimula fueron particularmente rápidos y dramáticos, también es cierto que en otros países cambios aparentemente menores han desatado dinámicas de fortalecimiento de actores sociales embrionarios. Esas dinámicas resultaron más importantes que lo predecible. Cualquier cambio en la conformación de las elites y en el ethos político puede constituir una "ventana de oportunidad" para la construcción de capital social.

Finalmente, en algunos casos las capacidades de autogestión y de participación política son desarrolladas por las propias comunidades, sin mayor apoyo externo. Pero la doble función de los agentes externos - como proveedores de las metodologías disponibles en este campo y como paraguas protector durante la fase de constitución de un actor social nuevo en el escenario microrregional- es esencial para que el capital social campesino se desarrolle con rapidez y seguridad.

\section{Bibliografía}

Arrow, K. (1994): Beyond general equilibrium, en Cowan y otros, Complexity: Metaphors, Models and Reality, Reading Massachusetts, Santa Fe Institute/Addison-Wesley.

Axelrod, R. (1997): The Complexity of Cooperation, Princeton, New Jersey, Princeton University Press.

Banco Mundial (1997): The World Bank Participation Sourcebook, http://worldbank.org/html/edi/sourcebook/.

Coase, R. (1937): The nature of the firm, Economica New Series, $\mathrm{N}^{\circ} 4$.

Cowan, G. y otros (1994): Complexity: Metaphors, Models, and Reality, Santa Fe, New Mexico, Santa Fe Institute.

Cruz, J.L. (1996): Estrategia complementaria y de coordinación del proceso organizacional para el desarrollo comunitario, Chiquimula, Guatemala, Proyecto de Desarrollo Rural para Pequeños Productores en Zacapa y Chiquimula (PROZACHI).

Durlauf, S. (1997): What Should Policymakers Know About Economic Complexity?, Working paper, Santa Fe, New Mexico, Santa Fe Institute.

Durston, J. (1992): Una mirada al Proyecto Zacapa-Chiquimula desde la perspectiva de las ciencias sociales, Informe de misión, Nueva York, UN Office of Project Services/PROZACHI.

Evans, P. (1996): Government action, social capital and development: Reviewing the evidence on synergy, World Development, vol. $24, \mathrm{~N}^{\circ}$ 6, Washington, D.C., The American University.

FIDA (Fondo Internacional de Desarrollo Agrícola) (1998): PROZACHI: La historia de un proyecto para el desarrollo de pequeños productores en Zacapa y Chiquimula, Roma, FIDA/ Ministerio de Agricultura y Ganadería.
Firth, R. (1963): Elements of Social Organization, Boston, Massachusetts, Beacon.

FLACSO (Facultad Latinoamericana de Ciencias Sociales) (1993): Descripción cualitativa de procesos sociales: el área de Quetzaltepeque, Ciudad de Guatemala.

Foster, G. (1961): The diadic contract: A model for the social structure of a Mexican peasant village, American Anthropologist, vol. 63, Washington, D.C.

Fox, J. (1996): How does civil society thicken? The political construction of social capital in rural Mexico, World Development, vol. $24, \mathrm{~N}^{\circ} 6$, Washington, D.C., The American University.

Galeano, L. y M. Yore (1994): Poder local y campesinos, Asunción, Centro Paraguayo de Estudios Sociológicos.

IAF (Inter-American Foundation) (1995): Inter-American Foundation Case Studies in Grassroots Development, Arlington, Virginia.

Lundius, J. (1998): Takarop: the Story of a Development Project Among Peasants in Zacapa y Chiquimula (summary), Roma, FIDA.

Mauss, M. (1990): The Gift: The Form and Reason for Exchange in Archaic Societies, Nueva York, Norton.

Mayer, A. (1966): The significance of quasi-groups in the study of complex societies, M. Banton (comp.), The Social Anthropology of Complex Societies, Londres, Tavistock.

Metz, B. (1998): Without nation, without community: The growth of Maya nationalism among Ch'ortís of eastern Guatemala, Journal of Anthropological Research, vol. 54, $\mathrm{N}^{\circ} 3$.

North, D. (1990): Institutions, Institutional Change and Economic Performance, Cambridge, Massachusetts, Cambridge University Press. 
Portes, A. (1998): Social capital: Its origins and applications in modern sociology, Annual Review of Sociology, $\mathrm{N}^{\circ} 24$.

Portes, A. y P. Landholt (1996): The downside of social capital, The American Prospect, $\mathrm{N}^{\circ} 26$.

PROZACHI (1995): Planificación participativa, Chiquimula, Guatemala.

Putnam, R. (1993a): Making Democracy Work: Civic Traditions in Modern Italy, Princeton, New Jersey, Princeton University Press.

(1993b): The prosperous community: social capital and public life, The American Prospect, $\mathrm{N}^{\circ} 13$.

RIMISP (Red Internacional de Metodologías de Investigación de Sistemas de Producción) (1996): Intercambio de experiencias sobre el papel de las organizaciones campesinas en el manejo de problemas y oportunidades de desarrollo agrícola, Taller electrónico, 2 de septiembre-31 de octubre, http://www. fidamerica.cl/conferen.htm.

(1998): Transferencia de proyectos de desarrollo agrícola y rural a los usuarios, Conferencia electrónica (13 a 31 de julio) http://fidamerica.cl/conferen.htm.
Rivera, R. (1996): Desarrollo rural sustentable: manual para la elaboración de proyectos, Caracas, Nueva Sociedad.

Swidler, A. (1986): Culture in action: symbols and strategies, American Sociological Review, vol. 51, $\mathrm{N}^{\circ} 2$, American Sociological Association.

Tendler, J. (1997): Good Government in the Tropics, Baltimore, Pennsylvania, Johns Hopkins Press.

Toledo, V. (1994): Planificación participativa del desarrollo local: guía metodológica, Temuco, Chile, Secretaría Regional de Planificación y Coordinación (SERPLAC).

Torres, V. H. (1998): Sistema de desarrollo local SISDEL: la participación comunitaria y vecinal en la formulación, seguimiento y evaluación de proyectos, Quito, Abya-Yala.

Wilson, D. S. (1997): Human groups as units of selection, Science, vol. 276, Washington, D.C., American Association for the Advancement of Science.

Wolf, E. (1966): Peasants, Englewood Cliffs, New Jersey, PrenticeHall. 